\title{
ORGANIZAÇÃO DE PESQUISA NO BRASIL: LIÇÕES DO PASSADO, PROPOSTAS PARA O FUTURO
}

\section{Fernando Galembeck*}

Instituto de Química, Universidade Estadual de Campinas, CP 6154, 13084-971 Campinas - SP

\begin{abstract}
RESEARCH ORGANIZATION IN BRAZIL: LESSONS FROM THE PAST, PROPOSALS FOR THE FUTURE. Chemical research in Brazil has grown significantly in the past 20 years, largely thanks to the Brazilian S\&T Development Program of the federal government (PADCT). However, the newly achieved levels of highly qualified manpower and research infra-structure require new research organization frameworks to make science, technology and innovation really useful and meaningful for the citizens. The current requirements for creating viable networks of academic and industry researchers are presented and discussed as well as some structural and procedural bottlenecks that have to be eliminated, to achieve maximum high-quality science, technology and relevant innovation output.
\end{abstract}

Keywords: R\&D networks; research organization; chemistry in Brazil.

\section{INTRODUÇÃO}

A pesquisa científica brasileira tem crescido muito e a produção resultante coloca o Brasil em uma posição respeitável no cenário internacional ${ }^{1}$. Por outro lado, a tecnologia e a inovação brasileiras já colecionam resultados notáveis em vários setores industriais e do agro-negócio, sendo que o Brasil é hoje o único país que consegue produzir combustíveis de fonte renovável e a preço vantajoso face ao do petróleo, sem qualquer subsídio e depois de décadas de pesquisa científica, tecnológica e de empreeendimentos bem planejados e executados ${ }^{2}$.

Entretanto, a pesquisa e a inovação são atividades em contínua mutação, porque seu assunto é sempre o novo. Os problemas, os temas, os instrumentos, os conceitos, as oportunidades e as circunstâncias são necessariamente novos, o que obriga à contínua renovação das formas, estruturas e práticas da atividade de pesquisa. Temos sempre de pensar se a organização existente é apropriada ou não e temos sempre de conceber novas formas, testando-as e avaliando-as.

\section{EXPERIÊNCIAS PASSADAS}

O Brasil sempre foi inovador, quanto à organização da pesquisa. Com um pouco de ironia, talvez tenhamos sido mais inovadores em organizar do que em fazer pesquisa. Entretanto, esse esforço produziu alguns resultados compensadores. No caso da Química, o maior programa de fomento dos últimos cinquienta anos foi o $\mathrm{PADCT}^{3}$, que foi um dos dois principais fatores para que chegássemos a uma situação muitíssimo superior à anterior e colocou a área da Química entre as líderes da atividade científica no país.

A isso somou-se o esforço de organização da comunidade científica representado pela SBQ. Como as contribuições do PADCT e da SBQ estão bem documentados, eles não serão re-examinados neste texto.

\section{SITUAÇÃO ATUAL}

Há hoje no Brasil três fatores muito positivos para a atividade de pesquisa, desenvolvimento e inovação:

1) existe uma população de doutores, em boa parte bem preparados para a pesquisa fundamental e tecnológica e que podem ser

*e-mail: fernagal@iqm.unicamp.br empregados com salários bem inferiores aos pagos em países desenvolvidos;

2) existe uma boa infra-estrutura de pesquisa, contando com equipamentos atuais e representativos do estado da arte;

3) existe um crescente interesse de empresários, a respeito da atividade de pesquisa. Quanto a isto, o setor químico se destaca pela existência de bons laboratórios, contando com uma boa tripulação de pesquisadores, em várias empresas ${ }^{4}$. Ainda mais importante que isto é a percepção, por muitos empresários, de que as atividades de $\mathrm{P} \& \mathrm{D}$ são parte essencial de suas estratégias.

A produção científica cresce continuamente e ocupa, cada vez mais, páginas das revistas mais prestigiosas da área. Entretanto, a maior parte dessa produção tem pouco significado estratégico, porque está pulverizada em um grande número de tópicos e temas. Portanto, torna-se obrigatório um esforço de avaliação da produção científica além do que tem sido freqüentemente praticado e que vai pouco além da contagem de números de trabalhos e de uma consideração, às vezes superficial ou desinformada, do "ranking" das revistas em que os trabalhos são publicados.

Observa-se, com enorme freqüência, que autores justifiquem seus esforços em uma ou outra direção apresentando as possíveis aplicações dos resultados da sua pesquisa. Infelizmente, essa justificativa é freqüentemente vazia porque os autores repetem apenas informações lidas em outros "papers", sem disporem de informação mais direta sobre as aplicações ou sobre patentes, propriedade intelectual, óbices econômicos ou ambientais. Além disso, o contato entre os pesquisadores de universidades e institutos com os profissionais de empresas é raro, impondo uma grande estreiteza às perspectivas dos cientistas, mesmo quando esses demonstram algum interesse pelas aplicações.

\section{PROPOSTAS}

\section{Programas cooperativos universidade-empresa}

No quadro atual, seria desejável que a indústria química e as indústrias fortemente dependentes de produtos ou processos químicos (isto é, quase toda a indústria e o agro-negócio) aumentassem o número de seus pesquisadores em pelo menos uma ordem de grandeza, em um período de uns poucos anos. Entretanto, com um mínimo de realismo, isso é improvável. Também seria necessário à indústria equipar-se com instrumentos e equipamentos que represen- 
tam investimentos substanciais e que são também improváveis.

No quadro atual há uma excelente possibilidade, que são os projetos cooperativos entre universidades e empresas. Muitas pessoas defendem essa cooperação e o número de opositores, mesmo nas universidades mais dominadas por radicais, tende a ser irrelevante. Além disso, há hoje um excelente conceito para fomentar esses projetos, que é o dos Fundos Setoriais.

O impacto dos Fundos já é importante, mas temos de reconhecer algumas limitações gravíssimas, que terminam por quase neutralizar o que poderia ser o seu impacto:

1) os executores de projeto são muito mais cobrados pelo rigor na execução financeira que pelos resultados dos projetos. Isso cria, dentro dos projetos, o imobilismo medroso que caracteriza uma grande parte da administração pública brasileira;

2) os valores de bolsas DTI, que são o principal instrumento de remuneração dos pesquisadores, são simplesmente vexatórios ${ }^{5}$;

3) os desembolsos totais dos Fundos estão muito aquém da sua arrecadação. Ou seja, existe uma malversação de fundos em grande escala, sendo recolhidas ao Tesouro importâncias elevadas que foram, por lei, destinadas ao fomento à pesquisa e inovação e à formação de recursos humanos.

As soluções para estes problemas seriam simples, se não exigissem um esforço e determinação que não são hoje encontrados nos gestores públicos de C\&T. Ao longo da minha vida, encontrei em agências gestores e técnicos muito interessados em resultados, mais do que em detalhes de execução financeira; considero que estas são pessoas realmente comprometidas com o bem público e que trabalham pelo desenvolvimento científico e tecnológico. Infelizmente, encontrei também (em todas as agências, sem exceção) pessoas que me pareceram mais interessadas em exercerem seus "pequenos poderes" e em protegerem-se dos auditores do que em trabalharem seriamente, obter resultados e defender os recursos públicos. Por outro lado, como eu também tenho uma experiência como gestor, colecionei muitos exemplos da sensibilidade dos auditores e dos tribunais de contas, face às necessidades legítimas dos executores de recursos públicos. Por esta razão, afirmo que os tribunais de contas mostram grande racionalidade e empenho na defesa do bem público face às justificativas dos gestores de recursos, ao contrário do que querem fazer entender alguns funcionários de enésimo escalão de agências de fomento.

Os valores das bolsas DTI mostram, de maneira exemplar, o quanto os responsáveis pela gestão de C\&T no Brasil parecem desatentos a um conceito simples, que é o da "etapa determinante do processo". Todo químico sabe que a velocidade de um processo depende crucialmente da sua etapa mais lenta. De nada adianta termos muitas etapas rápidas se todas elas conduzirem ao congestionamento causado por uma única etapa lenta. Além disso, como ensinava o Prof. Simão Mathias: "nenhuma corrente é mais forte do que o seu elo mais fraco". O mesmo ocorre com um projeto de pesquisa: ele tem de ser executado por pesquisadores, que devem ser recrutados, selecionados e remunerados. O regimento das bolsas DTI é pródigo em barreiras e oferece remunerações ridículas. Por outro lado, estas bolsas são o único instrumento efetivo para remuneração de uma grande parte dos pesquisadores brasileiros, de onde se conclui que a C\&T brasileira, especialmente a sua parte mais próxima das aplicações, está sendo conduzida por uma população de segunda classe.

Esta situação é tão grave que ela não pode ter sido produzida por um descuido. Ao contrário, ela reflete uma ideologia e uma postura de muitos cientistas e ex-cientistas brasileiros: a de que a pesquisa básica deva recrutar os grandes talentos, deixando a pesquisa aplicada e o desenvolvimento de produtos e processos entregues aos menos brilhantes.
Esse é um erro monumental, que foi denunciado por Pawel Krumholz ${ }^{6}$, há quarenta anos: acontece que as atividades de aplicação ou desenvolvimento são mais caras e envolvem riscos muito maiores que as atividades de pesquisa laboratorial ou aquelas executadas no computador. Uma explosão de 2 décimos de g de alguma substância no laboratório é muito diferente de uma explosão de $2 \mathrm{~kg}$ do mesmo material, na planta piloto. Se tivermos de escolher, onde queremos a pessoa mais capaz: no laboratório ou na planta piloto? Ou na indústria? Olhando-se as tabelas de valores de bolsas pagas pelas agências, fica claro que a pesquisa "de ponta" é muito melhor remunerada que o trabalho sólido de inovação.

\section{Desoneração}

O debate das políticas científicas está freqüentemente centrado em umas poucas questões, sendo sempre dominado pelas discussões sobre o montante de recursos disponíveis. Isso empobrece o debate, que deveria estar centrado em propostas, sendo validado pelos resultados de avaliações.

Um exemplo histórico é o dos "Finepões", que durante os anos 70 e parte dos anos 80 foram instrumentos essenciais ao desenvolvimento científico nacional. Grande parte dos projetos se destinava à aquisição de equipamentos e materiais de consumo importados. Por outro lado, estes eram normalmente adquiridos dos representantes brasileiros dos fabricantes, pagando-se elevadas taxas e impostos. Resumo: metade das dotações era simplesmente devolvida ao governo na forma de impostos ou remunerava empresas intermediárias ${ }^{7}$. A adoção de práticas de importação direta foi, durante muitos anos, uma quase exclusividade do CNPq e da Fapesp - que não eram então as principais fontes de recursos para a compra de equipamentos!

Visto esse exemplo histórico, encontramos hoje um grande número de entraves à atividade de pesquisa, impostos pelos próprios órgãos do governo, especialmente o federal. Este texto aponta mas não se propõe a discutir esses muitos entraves, que se localizam em vários pontos da administração federal, como a Anvisa, Ibama, Polícia Federal, Exército, legislação trabalhista, aduana e outros.

Não creio que eu esteja fazendo nenhuma afirmação temerária se afirmar, ainda que sem provas imediatas, que as práticas administrativas públicas brasileiras não estão isentas dos males da corrupção. Um bem conhecido lema da corrupção administrativa é "criar dificuldades para vender facilidades". Quanto dinheiro do orçamento brasileiro de C\&T é hoje usado para pagar "facilidades"?

Portanto, qualquer programa conseqüente de incremento da atividade brasileira em C\&T\&I tem de tratar seriamente da desoneração dessas atividades, da eliminação dos múltiplos entraves que impedem que mais resultados concretos surjam. $\mathrm{O}$ simples aumento da alocação de recursos, a persistirem instrumentos falhos como os atuais, significa um aumento dos desperdícios.

O exemplo mais brilhante de desoneração, nos últimos anos, foi a criação dos "grants" do CNPq. Esse notável instrumento merece uma avaliação cuidadosa, para que seja mantido, valorizado e, na medida do necessário, aperfeiçoado. Tal instrumento foi repetidamente proposto por várias pessoas no passado, tendo sido finalmente adotado na atual gestão do $\mathrm{CNPq}^{8}$.

Neste momento, o principal aperfeiçoamento necessário aos "grants" é o aumento do número de bolsas de produtividade de pesquisa, com o que os "grants" passarão a beneficiar uma população grande e merecedora, que hoje não tem acesso aos seus benefícios.

\section{Institutos virtuais e redes}

No segundo semestre de 2003 houve uma extensa discussão 
pública sobre a organização da pesquisa em nanotecnologia, que é paradigmática e por isso mesmo escolho como foco deste item. Esta discussão esteve polarizada entre a centralização das atividades em um grande centro de excelência em nanotecnologia, ou na sua distribuição entre redes de pesquisa e institutos virtuais.

Já o relatório Tundisi havia tratado dessa questão propondo a criação de redes de pesquisa, o que se materializou quando o $\mathrm{CNPq}$ criou quatro redes, em 2002, e quando foram aprovados, em renhida competição, três Institutos do Milênio afins à nanotecnologia: o Instituto do Milênio de Materiais Complexos, o de Nanociência e o de Rede de Pesquisa em Sistema em Chip, Microsistemas e Nanoeletrônica.

O acerto dessas políticas de descentralização na organização da pesquisa em nanotecnologia ficou absolutamente claro em um evento realizado em julho de 2005 em São Paulo, a Nanotec, que consistiu em uma feira e um congresso internacional. Na feira estiveram expostos mais de cem produtos de um grande número de laboratórios universitários (vários deles vinculados aos Institutos do Milênio) e do IPT, além de produtos que já estavam sendo lançados por empresas. Ou seja, a descentralização produziu resultados notáveis, muito superiores aos oferecidos pelos grupos que foram no mesmo período privilegiados como "centros de excelência" com maciços aportes de recursos, em base não-competitiva.

Esta é uma demonstração prática e recente da validade do que considero que seja o principal elemento de uma proposta para a organização da pesquisa em química, no Brasil. Os elementos dessa proposta são:

1) O fomento deve privilegiar os institutos virtuais, redes de grupos qualificados ou associações entre instituições de pesquisa e empresas, em bases competitivas, descartando-se a idéia das grandes unidades "de excelência", tal como teria sido o "Centro Brasileiro de Pesquisas Químicas". A principal diferença entre o que foi praticado no PADCT e esta proposta atual está no seguinte: enquanto o PADCT fomentou grupos de pesquisa, programas de graduação e pós-graduação, bibliotecas e facilidades piloto multi-propósito ${ }^{9}$, o que faz sentido fomentar hoje são as formas de associação entre grupos de pesquisa, instituições de ensino e de pesquisa, empresas e outros atores que possam contribuir para a inovação, trabalhando em conjunto.

2) O fomento deve ser focalizado em projetos definidos pelos responsáveis pelos institutos, redes ou associações entre universidades e empresas, submetidos a processo competitivo. A definição a priori de objetivos por grupos de pessoas mais ou menos vinculadas a governos não deve ir além dos grandes objetivos políticos. A temática, as metas e os futuros produtos devem ser definidos a partir de estratégias empresariais bem precisas, de vários níveis e visando atividades em todas as escalas, desde as pequenas empresas de base tecnológica até as mega-corporações.

3) Os resultados dos exercícios prospectivos devem ser sempre amplamente divulgados e disponíveis às empresas e instituições de pesquisa para que estas os usem, na medida da sua utilidade, na definição dos seus próprios objetivos. Por outro lado, é preciso reconhecer que a atividade de inovação envolve sigilo, em grande escala. Portanto, as definições de objetivos específicos e metas devem ser deixadas para os postulantes e executores de projetos, cabendo aos órgãos formuladores de políticas a definição de objetivos e metas agregados e não o seu detalhamento.

4) O sistema de pesquisa tem de estar apoiado em uma poderosa rede de equipamentos, bem instalados, mantidos e operados por pessoal competente. Não há nenhuma necessidade de se concentrar equipamentos para pesquisa química em uma ou em poucas facilidades, a não ser no caso de equipamentos que pelo seu próprio valor sejam necessariamente singulares, como os reatores nucleares e aceleradores de partículas. Nesse ponto, é essencial não esquecer o exemplo da Codetec: se as suas facilidades estivessem distribuídas em mais de um local, dentro do razoável, pelo menos uma parte delas estaria sendo utilizada. A sabedoria popular afirma que não se coloca todos os ovos em um só cesto.

4) A atividade de pesquisa executada por grupos isolados ainda tem e sempre terá uma enorme importância, seja na introdução de novos temas, seja na familiarização dos pesquisadores com áreas de altíssimo risco e na eventual obtenção de sucessos de baixa probabilidade. $\mathrm{O}$ apoio a essa atividade exige a manutenção de "balcões" como os dos atuais editais universais do CNPq e o dos auxílios individuais das agências estaduais. O nível de fomento a projetos individuais deve ser uma decisão política de alto nível e ele não pode ser quantitativamente irrelevante. Por outro lado, é óbvio que a existência de recursos abundantes de fomento para projetos individuais é um desestímulo ao engajamento de pesquisadores nos projetos estratégicos e coletivos, especialmente os de interação com empresas.

\section{TRANSPARÊNCIA E SIGILO}

Há um conflito latente na organização da pesquisa, entre transparência e sigilo. Empresas usam recursos públicos largamente, especialmente nos países mais desenvolvidos e é necessário prestar contas desses recursos. Por outro lado, as estratégias empresariais exigem controle de informação e sigilo, já que se trata de estratégias de negócios.

$\mathrm{Na}$ sistemática brasileira de fomento à pesquisa, na qual se gasta muita energia para avaliar projetos e pouco se trabalha na avaliação de seus resultados e impactos, o conflito entre transparência e sigilo é insolúvel.

Entretanto, bastaria deslocar o foco das avaliações, equilibrando-se a importância das análises feitas antes da execução, imediatamente após a execução e (digamos) três anos depois de concluído o projeto, para atenuar grandemente este conflito.

Obviamente, isto exige uma perspectiva temporal diferente da atual, em que ministros duram meses ou poucos anos em seus cargos e as mudanças de ministros implicam em mudanças de políticas e práticas, bem como no abandono de programas.

Embora mudanças como estas pareçam à primeira vista impensáveis, é forçoso reconhecer alguns progressos que ocorreram nas últimas décadas: o PADCT foi muito inovador ao introduzir nos anos 80 um orçamento pluri-anual, o que era então desconhecido. Por outro lado, os orçamentos da República são hoje organizados dentro de PPAs, que são pluri-anuais. Basta que estes não sejam desfigurados continuamente, para que atinjamos o mínimo de estabilidade exigido pela prática da inovação.

\section{PROPRIEDADE INTELECTUAL}

Em qualquer sistema contemporâneo de pesquisa e inovação, as questões de propriedade intelectual têm uma grande importância. Infelizmente, no sistema universitário brasileiro dá-se muito pouca atenção a patentes, como regra. Professores e alunos lêem livros e "papers", mas não patentes.

Nas áreas de ciências da matéria, biológicas, agrárias, das engenharias e da saúde a prática da proteção da propriedade intelectual foi sempre episódica e esporádica, com algumas poucas exceções, especialmente a da Unicamp. Entretanto, o sucesso alcançado pelos pioneiros foi estimulante para outros docentes e motivou 
algumas instituições ${ }^{10}$ a se organizarem para protegerem sua propriedade intelectual e dela colherem benefícios.

$\mathrm{O}$ ensino de ciências e tecnologia no Brasil ignora as patentes, com honrosas exceções. Os conteúdos curriculares dispostos nas Diretrizes Curriculares aprovadas no Conselho Nacional de Educação ${ }^{11}$ não dão importância à preparação do aluno para a consulta a patentes, como fonte de informação técnica.

A pós-graduação é o caso mais lamentavelmente notório de descaso com a propriedade intelectual. O sistema brasileiro de pósgraduação é uma grande realização nacional e o crescimento da produção científica brasileira é motivo de orgulho para todos os brasileiros. Portanto, estamos formando, cada vez mais intensamente, recursos humanos altamente qualificados para a investigação acadêmica e que deveriam ser qualificados para a pesquisa tecnológica e a inovação.

Por outro lado, qualquer exame de projetos submetidos às agências e de teses de mestrado e doutorado revela a sistemática ausência de referências a patentes ${ }^{12}$. Portanto, a quase totalidade dos mais qualificados recursos humanos produzidos nas universidades brasileiras não lê e nem escreve patentes. Isso tem várias conseqüências graves que exigem correção. Algumas propostas relevantes foram formuladas pelo autor ${ }^{13}$. Esse problema tem uma importante dimensão ética que foi tratada em um outro texto ${ }^{14}$.

\section{CONCLUSÃO}

Novos tempos exigem novas propostas, novas posturas e novas formas de organização. A gestão de C\&T\&I no Brasil mostrou-se ousada e criativa, em muitos momentos, e alguns dos resultados obtidos são muito positivos. Entretanto, é preciso abandonar idéias e formatos superados, criando e ousando. Tal como no passado, um papel essencial, nesse processo, pertence à comunidade científica. Entretanto, esse papel tem de ser desempenhado priorizando o bem comum, mais que os pequenos ou grandes ganhos individuais ou grupais.

\section{REFERÊNCIAS}

1. Pinto A. C.; de Andrade; J. B.; J. Braz. Chem. Soc. 2004, 15, 161.

2. Macedo, I;, Conferência, Sustentabilidade na geração e uso de energia no Brasil, Unicamp, Campinas, 2002.

3. Gama, A. A. S.; Quim. Nova 2001, 24, 717.

4. Galembeck, F.; J. Braz. Chem. Soc. 2005, 16, 123.

5. http://www.cnpq.br/bolsas_auxilios/normas/is0605.htm\#dti, acessada em Julho 2005.

6. Vichi, E. J. S.; Quim. Nova 1983, 6, 152.

7. Galembeck F.; Mesa-redonda sobre financiamento da pesquisa, $34^{a}$. Reunião Anual da SBPC, Campinas, 1982.

8. Relatórios do GEA, Grupo Especial de Acompanhamento do PADCT II, elaborados anualmente entre 1989 e 1996 e depositados no MCT.

9. Informação do autor: o PADCT contribuiu fortemente para a criação e operação de duas plantas-piloto multi-propósito: um projeto apoiado foi o da Nortec, empresa associada à Norquisa. Esta planta passou por altos e baixos mas hoje se constitui em um caso de sucesso. A outra foi a planta da Codetec, empresa presidida por Rogério C. Cerqueira Leite que operou até meados dos anos 90. Depois de alguns sucessos e insucessos e do prematuro falecimento de José Carlos Gerez, terminou por ser vendida a um empresário cujo nome pode ser lido com frequiência no noticiário policial. Encontra-se hoje inoperante, representando o sucateamento de um importante patrimônio e um exemplo dos descaminhos a que está sujeito o bem público.

10. http://www.usp.br/jorusp/arquivo/1999/jusp485/manchet/rep_res/rep_int/ pesqui2.html, acessada em Abril 2005.

11. http://www.mec.gov.br/Sesu/diretriz.shtm\#diretrizes, acessada em Abril 2005.

12. http://www.desenvolvimento.gov.br/sitio/sti/proAcao/proIntelectual/ proInt_Seminarios.php, acessada em Abril 2005.

13. http://www.cgee.org.br/cncti3/Documentos/Seminariosartigos/ Gestaoeregulamentacao/DrFernando Galembeck.pdf, acessada em Julho 2005.

14. Galembeck, F. Em Ethical Issues of Nanotechnology; Third Session of the World Commission on the Ethics of Science Knowledge and Technology, Rio de Janeiro, RJ, 2004, vol. 1, p. 127-132. 